\title{
Mass on chest X-ray
}

Geruza Alves da Silva, José Carlos Manco, João Terra Filho, Heloísa Glass, Fernando Augusto Soares

A 22-year-old man was admitted to hospital with a 14-kg weight-loss over the last 14 months, and an abnormal chest X-ray. Physical examination revealed signs of consolidation over the left hemithorax, fever, tachypnoea and tachycardia. Computed tomography (CT) was performed (figure 1) and one liter of bloody fluid was drained by thoracentesis. Abdominal CT scan was normal.

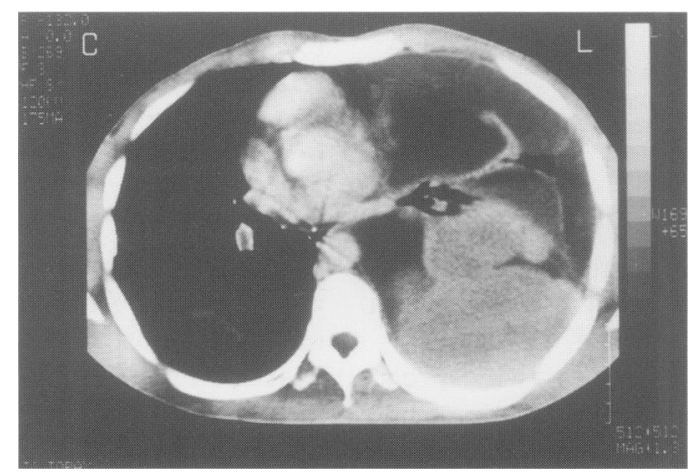

\section{Questions}

Department of Clinical Medicine, Pulmonary

Care Division, Faculty of Medicine of Ribeirão Preto

USP, Ribeirão Preto, São Paulo, Brazil

GA da Silva

JC Manço

JT Filho

H Glass

FA Soares

Figure $1 \mathrm{CT}$ scan of the thorax after intravenous

1 Describe three abnormalities on the thoracic CT scan

2 What are the three most probable causes of the abnormalities seen? 


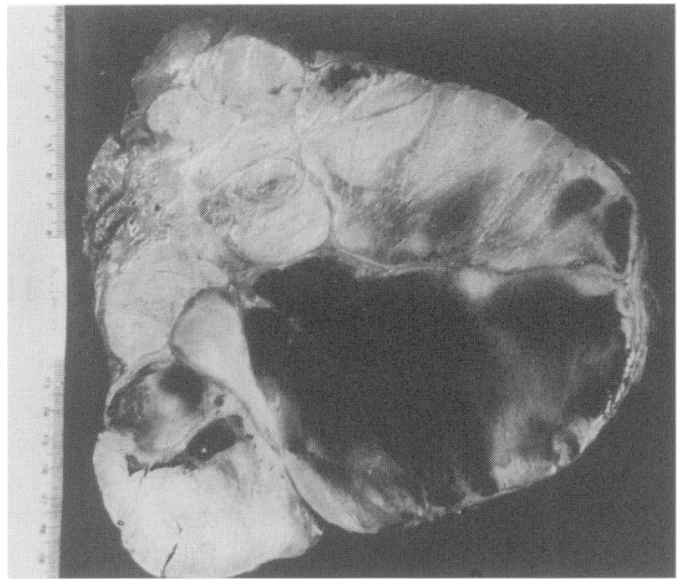

Figure 2 Anatomical aspect of the tumour; most of it was necrotic material and less than $5 \%$ of the total mass was residual lung

\section{Answers}

QUESTION 1

The CT of the thorax shows a posterior pleural-based mass with irregular margins. A cystic area with air-fluid level is present and lung parenchyma is compressed.

Full examination showed a widespread involvement of the left hemithorax. The tumour mass progressively filled the entire lower half of the cavity, depressing the diaphragm and shifting the mediastinum to the opposite side without infiltrating it.

\section{QUESTION 2}

The differential diagnosis must consider the following main causes of chest wall mass in young adults ${ }^{1,2}$ : Askin's tumour, Ewing's sarcoma, rhabdomyosarcoma, neuroblastoma, and malignant lymphoma.

The immunohistochemical profile of the aspirated material showed positivity for vimentine, S-100 protein, synaptaphysin and neuronspecific enolase, with no expression of cytokeratin AE1/AE3, carcino-embryonic antigen, epithelial membrane antigen or common leukocyte antigen. These findings allowed the diagnosis of malignant peripheral neuroectodermal tumour.

\section{Follow-up}

The patient received a multitherapeutic schedule of treatment starting with chemotherapy and $4500 \mathrm{cGy}$ of radiotherapy to obtain a reduction of the compromised area in the thorax and thus minimise symptoms and render the tumour resectable., ${ }^{1,3}$ Surgery was performed six months after the diagnosis. Examination of the surgical specimen revealed a huge tumour weighing $4.07 \mathrm{~kg}$ and measuring $30 \times 27 \times 17 \mathrm{~cm}$ (figure 2). Histologic material (figure 3 ) confirmed the cytological data. A little nodule extirpated from a buttock

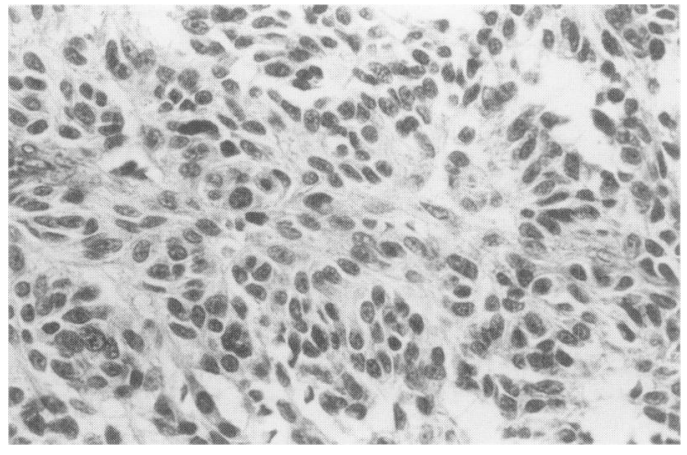

Figure 3 Histology of the tumour demonstrated a high level of cellularity represented by blocks of small cells with an oval and hyperchromatic nucleus and a finely fibrillar cytoplasm, with frequent pseudorosette arrangement

revealed a distant metastasis. The patient remained clinically free of disease 14 months after surgery.

\section{Discussion}

A thoracopulmonary tumour is a rare event in young adults. Among the possible causes is an unusual kind of neurogenic tumour, first described in 1979 by Askin et $\mathrm{al}_{,}{ }^{4}$ as a primitive peripheral neuroectodermal tumour of the thoracopulmonary region. Rib involvement is common. Recurrence and metastasis occur more frequently to the same hemithorax (lung, soft tissue chest wall, diaphragm and bone). Constitutional symptoms such as malaise, weight loss and fever, plus dyspnoea, dry cough, and a painful or painless mass in the chest wall are common. Ewing's sarcoma is the most closely related differential diagnosis. Chest X-ray and CT are useful diagnostic methods to indicate when Askin's tumour must be considered in the differential diagnosis. ${ }^{2,5}$ The most common finding is pleural involvement with effusion and/or a frequently large, unilateral, intrathoracic, pleural-based tumour image, showing mixed attenuation at CT, after intravenous injection of contrast; cystic areas may be present, corresponding to haemorrhagic and necrotic foci as well as calcic areas and lymphadenopathy. Prognosis is poor, with a mean survival of eight months, ${ }^{4,5}$ despite the use of a combined therapeutic schedule for control of dissemination (chemotherapy) and local tumour growth (radiotherapy and surgical resection). In our patient, however, this therapy has ensured considerable improvement in the quality of life for a period of at least 14 months.

\section{Final diagnosis}

Primitive peripheral neuroectodermal tumour of the thoracopulmonary region (Askin's tumour).

Keywords: Askin's tumour, neuroectodermal tumour
1 Kumar APM, Green A, Smith JW, Pratt CB. Combined therapy for malignant tumor of the chest wall in children. $\mathcal{F}$ Pediatr Surg 1977; 12: 991 -9.
2 Fink IJ, Kurtz DW, Cazenave L, et al. Malignant thoracopulmonary small-cell ('Askin') tumor. $A 7 R \quad 1985$ 143: $517-20$ 
3 Shamberger RC, Grier HE, Weinstein JH, et al. Chest wall tumors in infancy and childhood. Cancer 1989; 63: 774-85.

4 Askin FB, Rosai J, Sibley RK, Dehner LP, McAlister WH. Malignant small cell tumor of the thoracopulmonary region in childhood: a distinctive clinicopathologic entity of uncertain histogenesis. Cancer 1979; 43: 2438-51.
5 Sabaté JM, Franquet T, Parellada JM, Monill JM, Olive E. Malignant neuroectodermal tumour of the chest wall (Askin tumour): CT and MR findings in eight patients. Clin Radiol 1994; 49: $634-8$.

\title{
Abdominal mass and haematuria
}

\author{
PM Hewitt, WY Lau, TM Mackenzie, KF To, AKC Li
}

The Chinese

University of Hong

Kong, Prince of

Wales Hospital,

Shatin, NT, Hong

Kong

Department of

Surgery

PM Hewitt

WY Lau

AKC Li

Department of

Urology

TM Mackenzie

Department of

Anatomical and

Cellular Pathology

KF To

Correspondence to

Professor AKC Li

Accepted 30 October 1996

A 19-year-old woman presented with left loin pain, macroscopic haematuria and a vague abdominal mass. Renal function, full blood count and coagulation screen were normal. Plain abdominal X-rays revealed a large soft tissue mass occupying the left side of the abdomen and on intravenous urography, the kidney and ureter were displaced laterally with blood clot in the calyces. A computed tomography (CT) scan of the abdomen was done (figure 1).

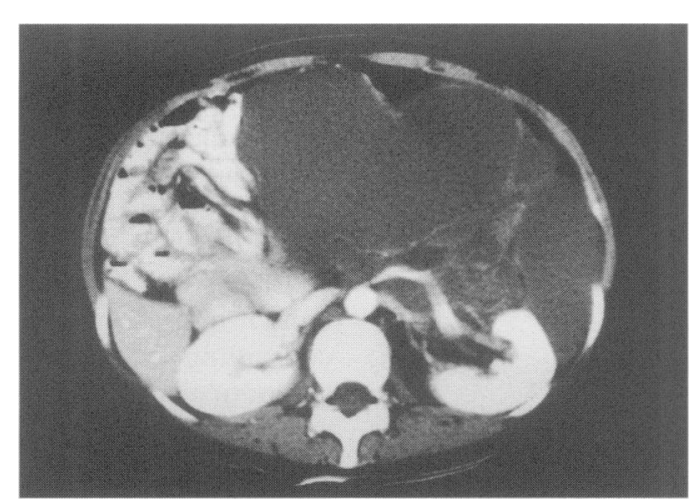

Figure 1 Abdominal CT scan

\section{Questions}

1 What does the abdominal CT scan show? 2 What are the differential diagnoses? 